\title{
A framework for designing a model for learning in small and medium enterprises
}

\author{
Nick Kearney, \\ Florida University \\ C/ Rei en Jaume 1, 2 \\ 46470 Catarroja \\ Valencia, Spain \\ +34-96-122-0389 \\ nkearney@florida-uni.es
}

\author{
Wilfred Rubens \\ IVLOS Institute for \\ Education, \\ Universiteit Utrecht \\ P.O Box 80.127 \\ 3508 TC Utrecht \\ Netherlands \\ +31-30-2533914 \\ g.f.l.m.rubens@ivlos.uu.nl
}

\author{
IVLOS Institute for \\ Education, \\ Universiteit Utrecht \\ P.O Box 80.127 \\ 3508 TC Utrecht \\ Netherlands \\ $+31-30-2532158$ \\ d.lockhorst@ivlos.uu.nl
}

\begin{abstract}
Previous research has indicated that formal learning activities, such as online courses and faceto -face training are, in many cases, not appropriate for small and medium enterprises (SMEs). Therefore in the European Work and Learn Together project a model for learning in SMEs is being developed that is based on the concept of the community of practice.

This paper describes a framework for designing this model for learning in SMEs. The principles of communities of practice are used to derive the basic elements. The initial design is based on three clusters of fundamentals (basic elements, framework and presence).
\end{abstract}

\section{Introduction}

Based on research in a recent EU-financed project it can be concluded that formal learning approaches (like courses and training) are, in many cases inappropriate for small and medium enterprises (SME) [1]. Learning takes place, but it is more usually of an informal, situated nature, and formal learning approaches are often rejected as unsuitable. The characteristics of this kind of learning have much in common with the learning that takes place in communities of practice. Therefore in the project Work and Learn Together (WLT), a model for learning in SMEs is being developed that is based on the concept of the community of practice. In this
Ditte Lockhorst

paper it is described how this model can be used to enhance learning in SMEs.

This paper initiates the process of creation of a provisional working model. Firstly the idea of the community of practice is briefly described. Secondly, necessary conditions for the emergence of a community are formulated, as well as some key questions that have to be answered in order to develop an appropriate model for learning in the SME context.

\section{Communities of Practices}

The foundations of the concept of the community of practice lies in the work of Lave and Wenger [2] and Wenger's later work [3], in which learning is understood principally as a process involving social participation.

Wenger, McDermott and Snyder define a community of practice as a group of people that share "a concern, a set of problems or a passion about a topic, and who deepen their knowledge and expertise in this area by interaction on an ongoing basis" [4]. It is important to note the focus in this definition on the deepening of knowledge and expertise. As throughout the work of Wenger learning is conceived of as an inherent part of the community of practice, and it takes place through interaction and participation.

According to these authors, three elements can be described as fundamental in the community of practice. The first element is called mutual 
engagement. Communities of practice evolve around common actions and ideas. Members engage with each other and interact around these shared elements and the community is defined by these interaction.

The second element is joint enterprise. Shared objectives presuppose a continuous renegotiation of objectives.

The third fundamental element for a community of practice is shared repertoire. This element includes all the behaviors involved in the community: routines processes, understandings, symbols and so on, that the community has acquired throughout its existence, it can be understood as a common culture.

These different elements provide a concept that serves as a framework in which to articulate informal interactions which are substantially different from the ostensibly hierarchical and formalized organizational structure of most companies. This causes a difficulty in the implementation of this kind of model. According to our research this kind of learning though it takes place- is largely unrecognized by the owners and managers of SMEs. As it does exist, it is logical to propose models that will facilitate and support these processes. However at the same time the lack of recognition of its existence may create attitudinal obstacles to their implementation.

\section{Structure of a model for learning in SMEs}

Based on the work of different authors, a general structure for a model for learning in SMEs can be described, based on three clusters of fundamentals.

\subsection{Basic elements}

The three basic elements (mutual engagement, shared repertoire and joint enterprise) that are shared in different descriptions of communities of practice, albeit using different vocabulary, can be viewed as central, in that without them it is unlikely that the benefits of a model based on the concept of a community of practice can be realized. In addition to these is an issue mentioned by Wenger, McDermott and Snyder [4] and Kimble and Hildreth [5], although from differing points of view. This is the question of motivation. In many communities participants can be described as self-motivated, but in the SME context it would be rash to assume this. It is therefore vital to ensure that participants are motivated. Wenger, McDermott and Snyder use the idea of value in this context. Participation in the community must be in some way of value to its members, this value may be of different kinds, though principal among these the learning that takes place, and the value participants may find in acting at times as experts for others. In addition to this and Daniel, Schwier and McCalla [6] identify a sense of belonging as important and this may also be viewed as a possible provider of value.

Questions that need to be answered in relation to these elements are

- What are the common interests and shared objectives of this potential "community of practice"?

- How do members of this potential community view themselves? Is there a shared identity among the potential participants?

- How do the potential members of this community currently engage/interact with each other?

- How can the potential value be demonstrated? Both before the start and during the life of the community?

\subsection{Framework}

Moreover there are a series of considerations to bear in mind in the design and maintenance of communities, or their cultivation, to use Wenger, McDermott and Snyder's term. One cluster of considerations can be denominated as the "framework": the configuration of the space in which the community exists, including aspects related to the tools used and the spaces and subspaces created and initial consensus-based norms that govern the way the community functions (though these may change). The idea of framework can however also be understood as an evolution over time. This includes not only the stages of emergence, but also the sense of history of the community, the rhythms of interaction, the interaction between familiar events and rites and spontaneous activity.

In relation to the framework different questions need to be answered, such as:

- What experience do potential participants have of online activity and interaction?

- Is there an identifiable set of norms and protocols that would be acceptable to potential members of the community?

- What kind of time commitment to the community is likely to be possible for participants? How often are they likely to connect to the community? 
- Is there a history of similar face to face community activity, either in the workplace or outside it, among the participants?

- What kind of regular activities might be seen as valuable elements of the community by potential participants?

\subsection{Presence}

The other cluster of considerations can be termed "presence". This includes all the elements relating to interaction, dialogue and the interrelation of the participants and the different roles they adopt at different times. In a sense these are elements that cannot be defined beforehand as they are emergent, and conditioned by the way in which the participants behave and interact within the community. From the purpose of learning in SMEs they are key because they constitute the processes through which learning will take place through participation in the community.

The idea of presence can be divided into three areas along the lines of Garrison and Anderson [7], who make a distinction between social presence, cognitive presence and teaching presence. Teaching presence is similar in nature to the idea of framework, we prefer however the idea of framework as an organizing concept since the idea of the teacher (though participants may adopt this role more or less explicitly at times) sits uneasily with the nature of the community of practice and would seem to lead away from informal processes to more formal contexts.

Social presence is described as the ability of participants to project themselves within the community and appear as real people, in other words, the sense of self and others within the community, which is of particular importance in an online context, where this kind of presence requires careful attention. It cannot be taken for granted, especially in an SME context where many participants may be less than familiar with the technology used and even initially uncomfortable with it.

Cognitive presence is described as the extent to which participants are able to construct meaning through sustained communication: this can be related to the idea of learning through participation (in this case in conversations) described in the context of communities of practice. It can be used as a term to aid thought about how learning is to take place in this community context. Examples of questions are:

- Are there natural leaders or champions within the potential community who could act as attractors for other participants?
- $\quad$ Are there identifiable peripheral experts who could be encouraged to participate sporadically in community activity?

- What interrelations exist between potential participants already?

- Are there cultural aspects or attitudes that may affect participation in the community?

- What kinds of interactive activity are likely to be most valued by potential members of the community?

It is impossible, and probably counter-productive, to describe previously the detailed characteristics of the community that will emerge. An appropriate approach to the design of a model in this context therefore must understand the headings outlined above as areas for exploration. Rather than design, participatory development is preferred. A range of questions such as those described above, should be explored in collaboration with the target group. This model for designing a framework for learning in SMEs should therefore be understood as a range of areas that require consideration, reflection and subsequent adaptive application to the particular SME context in which the model will be developed.

\section{References}

[1] Rubens, W., D. Lockhorst and W. Admiraal, "Kansen voor e-learning in het MKB" (Opportunities for e-learning in SMEs), Opleiding en Ontwikkeling, Elsevier, The Hague, in press.

[2] Lave, J. and E. Wenger, Situated learning: Legitimate Peripheral Participation. Cambridge University Press, Cambridge. 1991

[3] Wenger, E., Communities of practice: Learning, meaning and identity, Cambridge University Press, Cambridge, 1998

[4] Wenger, E., R. McDermott and W. Snyder, Cultivating communities of practice: a guide to managing knowledge, Harvard Business School Press, Boston, 2002

[5] Kimble, C. and P. Hildreth, Communities of Practice: Going one step too far? University of York, York, 2004. Accessed 22/2/2006 http://www.aim2004.intevry.fr/pdf/Aim04_Kimble_Hildreth.pdf

[6] Daniel, B., R.A. Schwier and G. Mcalla, Social capital in virtual learning communities and distributed communities of practice, Canadian Journal of Learning and Technology, University of Calgary, Calgary, 2003 
[7] Garrison, D.R. and T. Anderson, E-learning in the $21^{\text {st }}$ Century. A Framework for Research and Practice. RouteledgeFalmer, London/New York, 2003 